\title{
Effects of Land Use Change on Vegetation Coverage of Typical Steppe Region Case in Xilin Gol Grassland
}

Daoriao $^{1}$, Jincai $\mathrm{Xu}^{1,2}$, Yinshan $^{1}$, Suriguga Bao ${ }^{1}$

\author{
${ }^{1}$ Inner Mongolia Normal University, School of Geographical Sciences, Hohhot 010022, China \\ ${ }^{2}$ Inner Mongolia land surveying and Planning Institute, Hohhot 010022, China \\ 土地利用变化对典型草原区植被覆盖的影响 \\ 以锡林郭勒草原为例
}

道日敖 ${ }^{1}$, 徐进才 ${ }^{1,2}$, 银山 ${ }^{1}$, 包苏日古嘎 ${ }^{1}$

1 内蒙古师范大学 地理科学学院, 呼和浩特 010022 , 中国

2 内蒙古土地调查规划院, 呼和浩特 010022 , 中国

\begin{abstract}
In this paper, 2000 - NDVI data 2014 Xilingol Grassland normalized difference vegetation index and land use Xilingol data, with the support of ENVI and Arcgis software, spatial and temporal variation in NDVI, analyzes Xilingol grassland vegetation cover condition the overall variation between distribution and its relationship with land use change. The results showed that: Xilingol grassland vegetation coverage change the overall trend is gradually decreasing from east to west, the eastern region is slightly higher than the western region, the southern region slightly north. Xilingol grassland vegetation coverage 15 years overall showing a rising trend. It shows the Xilingol League nearly 15 years of land use planning aspects and ecological protection work has achieved significant benefits.
\end{abstract}

Keywords: grassland resources; NDVI; temporal and spatial variation; land-use change; Xilingol grassland

\section{摘要}

本文以 2000-2014 年锡林郭勒草原归一化差异 植被指数 NDVI 数据与锡林郭勒盟土地利用现 状数据为基础, 在 ENVI 和 Arcgis 软件的支持 下, 以 NDVI 的时空变化特征入手, 分析了锡 林郭勒草地植被覆盖状况的总体分布状况及 之间的变化规律及其与土地利用变化的关系。
结果表明: 锡林郭勒草原植被覆盖率整体变化 趋势是由东向西逐渐减小, 东部地区略高于西 部地区, 南部地区略高于北部地区。15 年间锡 林郭勒草地植被覆盖率总体呈现出上升趋势。 表明了锡林郭勒盟近 15 年的土地利用规划方 面和生态保护工作取得了显著地效益。

关键词: 草地资源; NDVI; 时空变化; 土地 利用变化; 锡林郭勒草地

\section{1. 引言}

锡林郭勒草原位于蒙古高原, 不仅是全国重要 的放牧畜牧业基地和牧区人民赖以生存的物 质基础, 也是中国北方和京津地区重要的绿色 屏障。作为中国农业自然资源中面积最大、最 重要的国土资源, 草地资源不仅是宝贵的自然 资源和生产资料, 也是重要的生态资, 不同程 度的退化不仅会造成草地面积锐减、草地生产 力下降、草地产量与质量降低, 而且还会引发 草地沙漠化、水土流失、生物多样性丧失等环 境问题和自然灾害频发等一系列生态问题; 不 仅严重威胁这畜牧业可持续发展, 而且使草地 生态系统环境急剧恶化, 造成了巨大的经济损 失, 严重阻碍了中国北方地区社会经济的可持 续发展 [1]。植被是地球系统中的活跃成员, 陆 地生态系统的任何变化必然在植被类型、数量 或质量方面有所响应[2]。植被覆盖度是指单位 面积内植被地上部分 (包括叶、茎、枝) 在地 面的垂直投影面积占统计区总面积的百分比 [3]。植被覆盖度指示了植被的茂密程度及植物 
Risk Analysis and Crisis Response in Big Data Era (RAC-16)

进行光合作用面积的大小, 是反映地表植被群 落生长态势的重要指标和描述生态系统的重 要基础数据, 对区域生态系统环境变化有着重 要指示作用[4]。归一化差分植被指数 NDVI- Normalized Difference Vegetation Index, 又可 以称标准化植被指数。是近红外波段与红色波 段的差异经二者之和校正后的结果，可以表现 出植被覆盖的空间结构分布密度及其生长状 况。NDVI 值在- 1 和 1 之间, 0 以下表示的是水、 雾、云类。 0 表示裸露地面或者是硬块岩石。 0 以上表示的是地面覆盖的植被。

近年来, 在气候变化和人类活动的双重作 用下, 蒙古高原资源环境问题日益突出, 愈来 愈引起国际社会，特别是从事生态、环境、资 源、水文、气候、地理、灾害和人文等研究的 学者的共同关注和重视, 开展了一系列的研究 工作。地处蒙古高原的内蒙古草地是中国重要 的生态屏障, 研究该地区植被覆盖的变化趋势 及与土地利用变化的关系, 会有利于了解中国 及相邻地区的生态环境的状况及趋势, 对下一 步土地利用规划及生态保护具有重大的指导 意义 [5-10]。

\section{2. 研究区概况}

\section{1 研究区确定原因}

中国是草地资源大国, 拥有的各类天然草地 39283 万公顷，约占国土面积的 $41 \%$, 仅次于 澳大利亚, 居世界第二位。它主要分布在年降
水量 400 毫米以上的干旱、半干旱地区, 南方 和东部湿润、半湿润地区以及东部和南部海岸 带等, 如图 1 。中国天然草地资源分布的 3 个主要区域: (1)北方温带草地区(2)青藏高原高 寒草地区(3)南方和东部次生草地区。

内蒙古草原 (图 2), 东起大兴安岭, 西 至居延海畔, 绵延 4000 多公里, 是欧亚大陆 草原的重要组成部分。全区草地总面积 7880 万公顷, 占全区国土总面积 $66.6 \%$, 占全国草 地面积的 $22 \%$, 位居全国首位。其中, 可利用 面积 6359.09 万公顷, 占全区草地总面积 $80.70 \%$ 。由于受东南海洋性季风和大兴安岭和 阴山山脉等山地隆起的影响, 全区水平分布地 带性天然草原植被, 从东到西可分为草甸草原 (森林草原)、典型草原、荒漠草原、草原化 荒漠和荒漠五大类。

草原在人类的生产和生活中, 特别是自然 环境的保护与改善中发挥着重大的、其他生态 系统所不可取代的重要作用。典型草原是内蒙 古草原的主体。总面积为 2767.35 万公顷, 占 全区草地总面积的 $35.12 \%$ 。典型草原是草原 带的最基本的类型, 也是全国最典型的草原区 域。内蒙古草原是我国北方重要的北方重要的 生态屏障, 锡林郭勒草原在其中发挥着举足轻 重的作用。因此对该区域进行植被覆盖度研究 能够反映出该区域生态环境的整体情况, 也能 够为我国北方生态政策及土地利用规划提供 科学依据。

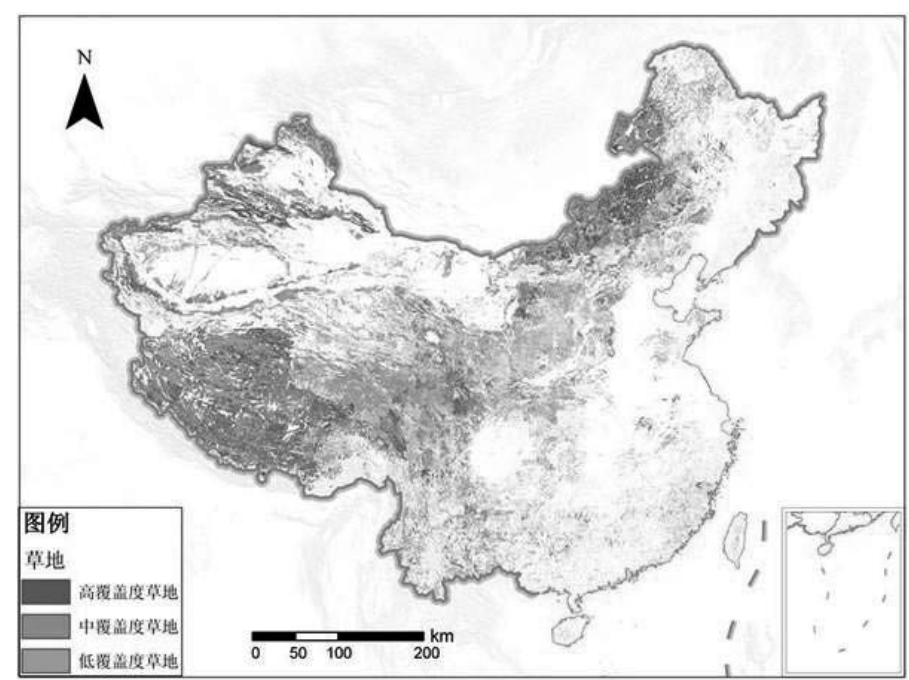

图 1 中国草地资源覆盖程度分布图（地理国情监测云平台） 
Risk Analysis and Crisis Response in Big Data Era (RAC-16)

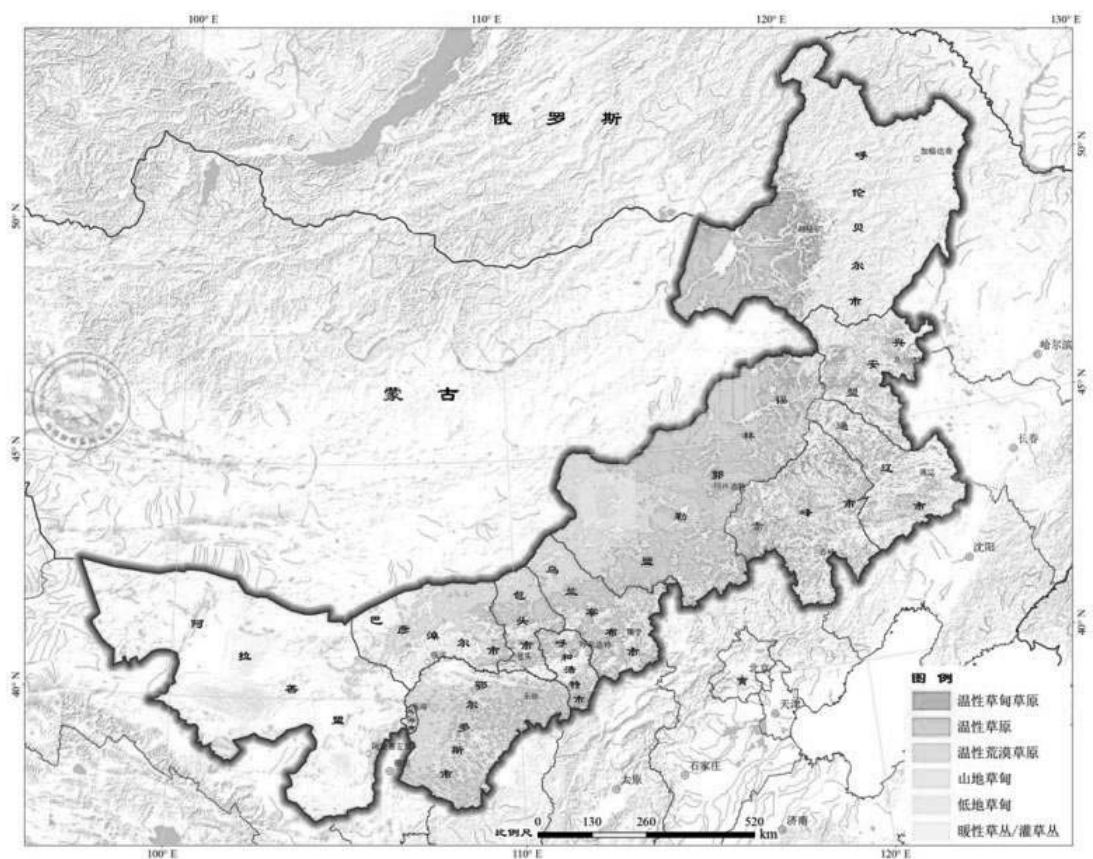

图 2 内蒙古草原分布图 (中国国家地理)

\section{2 研究区概况}

锡林郭勒盟是内蒙古自治区所辖盟, 位于 中国的正北方, 内蒙古自治区的中部, 驻地锡 林浩特市（图 3)。这里既是国家重要的畜产 品基地, 又是西部大开发的前沿, 是距京津唐 地区最近的草原牧区。地处东经 $115^{\circ} 13^{\prime}-117^{\circ} 06^{\prime}$ 、北纬 $43^{\circ} 02^{\prime}-44^{\circ} 52^{\prime}$, 东北、 华北、西北交汇地带。锡林郭勒盟是一个以高

平原为主体, 兼有多种地貌的地区, 地势南高 北低, 东、南部多低山丘陵, 盆地错落其间, 为大兴安岭向西和阴山山脉向东延伸的余脉。 西、北部地形平坦, 零星分布一些低山丘陵和 熔岩台地, 为高原草场, 海拔在 800-1800 米 之间。其主要气候特点是风大、干旱、寒冷。 蒸发量最大值出现在 5-6 月份。年日照时 数为 $2800-3200$ 小时, 日照率 $64-73 \%$, 无霜期 110 - 130 天。

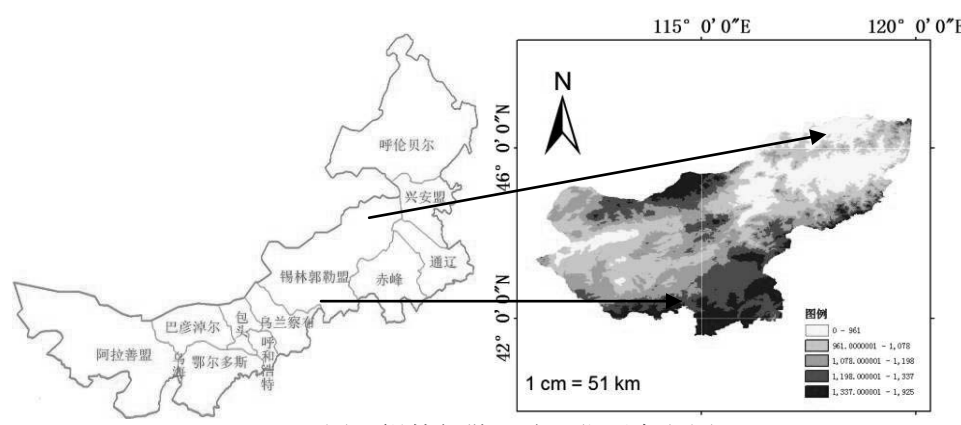

图 3 锡林郭勒盟地理位置高程图 
Risk Analysis and Crisis Response in Big Data Era (RAC-16)

锡林郭勒草原位于内蒙古自治区锡林郭 勒盟境内, 从东向西排列为草甸草原、典型草 原、荒漠草原, 以典型草原为主 (图 4)。面 积 107.86 万公顷, 是世界闻名的大草原之一, 也是中国四大草原之一内蒙古草原的主要天 然草场。锡林郭勒草原是中国境内最有代表性 的丛生禾草根茎禾草 (针茅、羊草) 温性真草 原, 也是欧亚大陆草原区亚洲东部草原亚区保 存比较完整的原生草原部分。保护区内生态环 境类型独特, 具有草原生物群落的基本特征, 并能全面反映内蒙古高原典型草原生态系统 的结构和生态过程。

锡林郭勒草原拥有丰富的自然资源, 以其 草场类型齐全、动植物种类繁多等特征而成为 世界驰名的四大草原之一, 属欧亚大陆草原 区, 境内有全国唯一被联合国教科文组织纳入
出。随着社会和经济的发展, 土地利用规划会 遇到工业化、城市化、产业结构调整、生态退 耕问题。锡林郭勒草原作为中国北方生态屏 障, 尤其需要土地利用规划提出更加完整系统 性的计划。土地利用规划在国家土地管理局科 技司出版教材中定义为: “土地利用规划（简 称土地规划) 是指人们为了改变并控制土地利 用方向, 合理组织土地利用结构, 提高土地生 产力, 根据社会发展需求和当地自然、经济、 社会条件, 对一定范围内, 进行空间的优化组 合和时间上实现优化组合的安排。” 所以每次 的土地利用变化会规划草地资源利用空间结 构和利用方向, 对于草地资源的合理利用和可 持续发展都会有重要的影响。

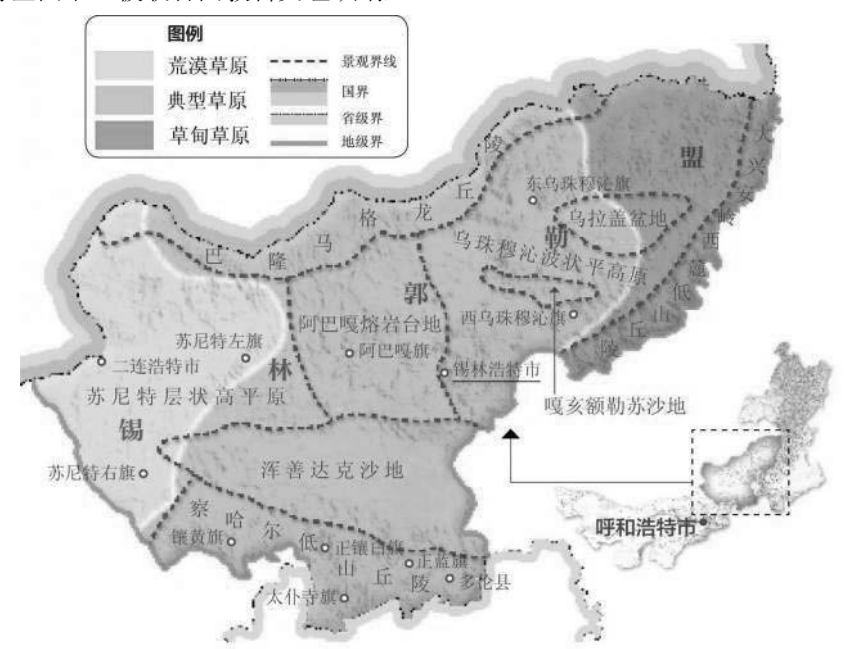

图 4 锡林郭勒草原分类图

国际生物圈监测体系的锡林郭勒国家级草原 自然保护区, 既是华北地区的重要生态屏障, 又是距首都北京最近的草原牧区, 是国家和自 治区重要的畜产品基地, 占全自治区的五分之 一。

\section{3 研究意义}

关于草地资源研究方面, 有着很多的气候 和降水对草地资源变化的影响类的文章 [11、 12], 却会很少提及土地利用规划。土地利用 规划直接关系到社会经济的可持续发展和社 会构建问题。我国人多地少, 人地矛盾尤为突

\section{3. 数据与方法}

\section{1 数据来源及处理}

\section{1 .1 遥感数据}

本文采用的遥感数据 NDVI 为锡林郭勒盟 2000 至 2014 年的 MODIS NDVI 产品数据 MOD $13 \mathrm{Q} 1$, 从美国宇航局 NASA 网站 (http://ladsweb.nascom.nasa.gov/) 直接下载。 MODIS NDVI 数据为 16 天合成的空间分辨率为 $250 \mathrm{~m}$ 的 Terra MODIS NDVI 数据集影像, 包 括俩景 $(h 25 \mathrm{v} 04$ 和 h26v04)。因为需要考虑 
Risk Analysis and Crisis Response in Big Data Era (RAC-16)

到冬季积雪问题，所以此论文只采用了每年的 4 到 10 月份 (植被生长季) 的数据, 即 097 305 的数据。下载的数据集在 MRT 软件中拼接转、 投影换格式后用 ENVI 软件对此遥感影像运 用最大值合成法 (Maximum value Composites [13]）和锡林郭勒盟边界线裁剪获得每月 NDVI 值, 合成每年平均值。再运用 Arcgis 软件 Zonal Statistics as Table 功能算出其每年平均值, 做 出 15 年间的锡林郭勒盟 NDVI 值变化的趋势 图, 用于锡林郭勒草原植被覆盖度时间变化分 析。

用 15 个年平均值的 NDVI 数据影响在 ENVI 软件中做出 15 年间平均的数据影像, 后用 Arcgis 软件出图 15 年间平均的和 2000年、2014 年数据图。分别用于空间格局分析和空间变化 分析。

\section{1.2 土地利用变化数据}

本文采用的土地利用数据是以 2000、2005、 2009 年 (因为涉及到保密问题, 不可以用某些 细节数据和近几年的数据, 所以在自己做出的 数据的基础上引用了师姐论文当中的数据转 移矩阵[14]）的 Landsat TM 影像为数据源, 将研究区土地利用类型划分为四类, 即耕地、 林地、草地、居民点及工矿用地。在此基础上, 分层提取目标地类, 结合实地考察, 最后生成 俩期土地利用类型转移矩阵图。

\section{2 研究方法}

本研究主要采用一元线性回归分析法对 2000 2014年锡林郭勒盟植被 NDVI 整体变化 趋势进行了分析。单个像元多年回归方程中的 趋势线斜率即为年际变化率。利用 NDVI 的序 列和时间序列的相关性来判断 NDVI 年际变化 的显著性。再根据公式 (1) 计算得到各时期 植被覆盖分布图, 将计算结果按等级按等间距 分为如下五个等级: 极低覆盖度 $(0-0.2)$ 、低 覆盖度（0.2-0.4）、中覆盖度（0.6-0.8）、高 覆盖度 $(0.8-1)$ 。

$$
\overline{N D V I}_{i}=\frac{1}{7} \sum_{j=4}^{10} N D V I_{j}
$$

式中: $j$ 表示第几月 $(j=4$ 至 10)

\section{4. 结果与分析}

\section{1 NDVI 时空变化特征分析}

\section{1.1 时空变化}

2000 2014 年锡林郭勒草原生长季 NDVI 总量 变化趋势如图 5。在研究时段内, 锡林郭勒草 原生长季 NDVI 总量呈波动式增长趋势, 增加 速率为 0.002 。2000 2010 年间, NDVI 变化波 动较为平缓, 且在 2001、2007、2009 年出现 低值期, NDVI 值分别为 $0.247448 、 0.248524$ 、 $0.248189 ; 2010$ 年后 NDVI 急剧增加, 至 2012 年达到最高值, 为 0.322197 。这说明研究期间 锡林郭勒草原的植被状况得到了改善, 表明了 生态保护与恢复工程[15、16]对植被生长的促 进作用。

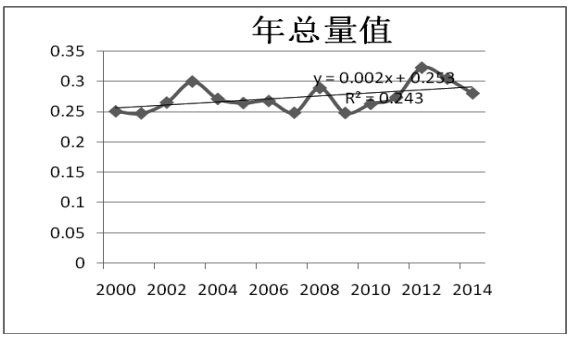

图 5 2000 2014 年锡林郭勒草地生长 季 NDVI 总量年际变化

\subsection{2 空间格局}

锡林郭勒草原 NDVI 的分布由于受经纬度地带 性的植被、气候、地形因素等的综合影响, 总 体呈现出从东北向西南方向递减（图 6)。位 于研究区东北部的东西乌珠穆沈旗地区植被 覆盖度较高, 尤其在东乌珠穆沁旗东北部地 区, NDVI 普遍高于 0.6 ; 而位于研究区西南部 的苏尼特右旗、镶黄旗地区植被极度稀少, 因 此该地区 NDVI 相对较低 (因荒漠草原和浑善 达克实地的分布)。从不同等级 NDVI 空间分 布来看, NDVI 值介于 0.6-0.8 间的地区主要分 布于东乌珠穆沁旗中部及西南部、西乌珠穆沁 旗东北部地区。另外, 在多伦县和太仆寺旗也 有零星分布; NDVI 值介于 0.4-0.6 间的地区主 要分布于西乌珠穆沁旗西南部、阿巴嘎旗地 区。另外, 锡林浩特市、正蓝旗也有少量分布; NDVI值介于 0.2-0.4间的地区主要分布于阿巴 嘎旗、正蓝旗、正镶白旗、太仆寺、苏尼特左 旗地区。 
Risk Analysis and Crisis Response in Big Data Era (RAC-16)

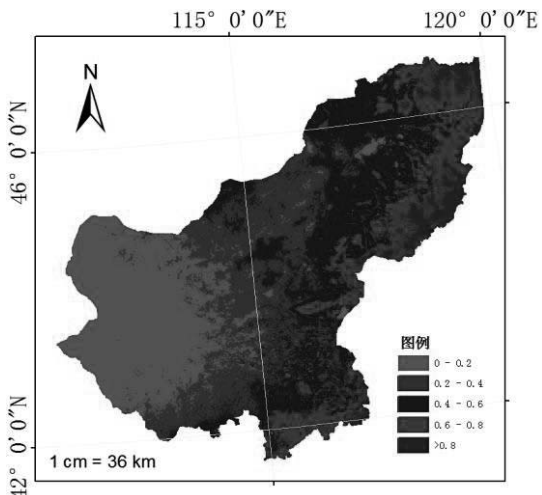

图 $62000 \sim 2014$ 年 15 年间 NDVI 平均值 分布图

\section{1.3 空间变化}

为了分析植被覆盖度的空间年国际变化, 分别 计算了 2000 年、 2008 年和 2014 年的锡林郭勒 草原的植被覆盖度（如图 7）。具体空间上的 变化为, 2014 年与 2000 年、 2008 年相比锡林 郭勒草地东部与东南部地区的植被覆盖度提 升, 其低覆盖度从西往东加大。按行政区来看,
东乌珠穆沈旗植被覆盖度明显上升。西乌珠穆 沁旗、锡林浩特市东部与南部也有显著提升。 总体而言, 2000-—2014 年间锡林郭勒草地植 被覆盖度呈现出由低等向高等转移的趋势。极 低覆盖度向低覆盖度的转移率较为显著。

\section{2 土地利用变化分析}

2000 年至 2005 年, 5 年当中各类型变化的面 积（图 8a）依次为: 草地、耕地、居民地及工 矿用地、林地, 其中只有耕地面积为减少, 其 它地类面积。作为研究区的主要且典型地类, 草地的转入面积为最大, 其中高覆盖度草地增 加了 $0.91 \%$ 。根据面积变化数据得知林地与草 地的面积增加, 这说明关于锡林郭勒盟的生态 保护和土地资源保护利用方面的工作已经开 始了有效的实施。

2005 年至 2009 年, 4 年当中各类型变化 的面积 (图 8b) 与 2000 年至 2005 年间的变化 大概相同, 也是草地面积的增加量为最大, 耕 地面积在持续减少当中。草地转入面积的部分 来自于耕地、林地和居民点工矿用地的减少部 分。这也就是说，这段期间的退耕还林草政策 在锡林郭勒盟的实施有了显著效果。

总的来说, 2000 至 2009 年间, 耕地面积
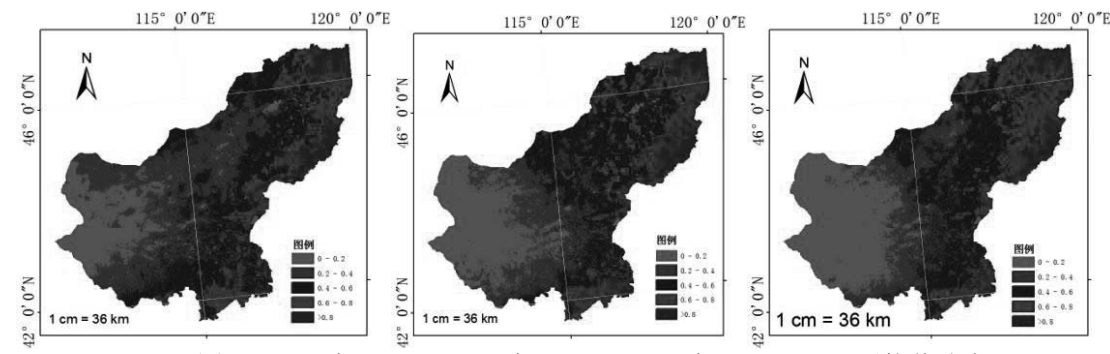

图 72000 年（a）、2008 年（b）、2014 年（c） NDVI 平均值分布
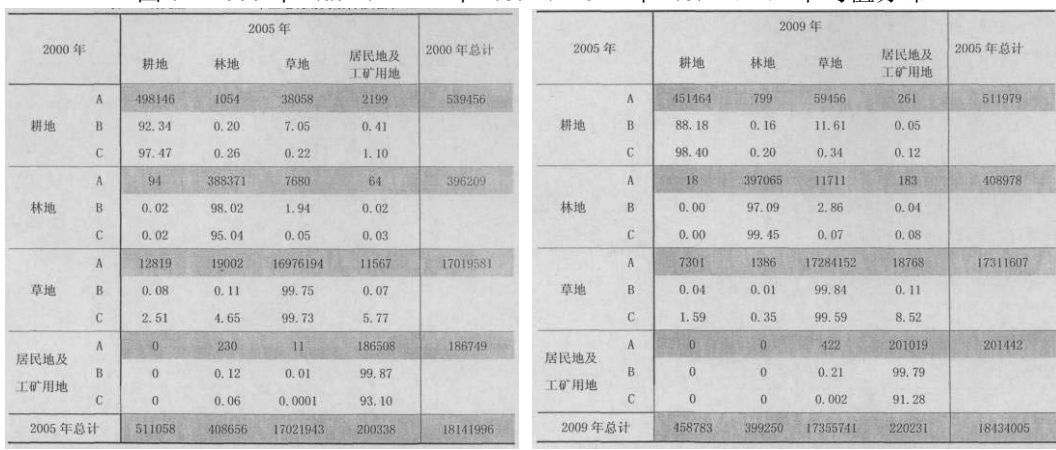

图 82000 年至 2005 (a)、2005 年至 2009 年（b）的土地利用类型转移矩阵 $\left(\mathrm{hm}^{2}\right)$ 
呈现出持续减少的趋势。草地的新增面积和转 移面积最多, 并且转入面积多于转移面积, 所 以草地面积呈增加趋势, 除了耕地外, 其它三 个地类的面积都有不同程度的增加。草地中, 极低覆盖度向低覆盖度的转移, 高覆盖度面积 也加大。锡林郭勒地区植被状况总体呈现好转 的趋势, 与近年锡林郭勒草地植被状况总体好 转的结论一致[17-20]。这说明了 21 世纪开始 的生态保护和退耕还林还草政策的实施在锡 林郭勒盟取得了显著地效果。

\section{3 土地利用变化对 NDVI 的影响}

2000 年国务院发布的《关于进一步做好退耕还 林还草试点工作的若干意见》; 国土资源部发 布《农业综合开发土地复垦项目管理暂行办 法》，合理规划用地，保护耕地。2007 年国务 院发布《关于严格执行有关农村集体建设用地 法律和政策的通知》; 《中华人民共和国耕地 占用税暂行条例》, 2008 年国务院发布《国务 院关于促进节约集约用地的通知》; 同时, 财 政部、国税局颁布了《耕地占用税暂行条例实 施细则》, 坚持“节约集约用地, 坚守耕地红 线”, 严格执行耕地补偿制度。2008 年, 《土 地调查条例》标志着我国土地调查工作步入了 法制化轨道; 2009 年, 国土资源部公布《土地 调查条例实施办法》, 同时颁布《土地利用总 体规划编制审查办法》，规范土地利用总体规 划的编制和审查报批程序, 提高土地利用总体 规划的科学性和可操作性。

在其《内蒙古自治区土地利用总体规划》 (2006-2020 年) 中提出: 土地利用结构不够 合理全区的林地相对集中分布在山区, 广大的 牧区、农区及农牧交错区是少林区, 反映出自 治区在土地利用上的单一性及用地结构的不 合理性。土地利用规划是一种空间规划, 它是 土地利用规划体系中的重要组成部分, 是土地 利用管理的 “龙头”。编制和实施土地利用总 体规划是解决各种土地利用矛盾的重要手段, 也是保证国民经济顺利发展的重要措施, 对实 现我国社会主义现代化建设具有重要意义和 作用。能够有效地解决土地利用中的重大问 题, 通过规划, 划分土地利用区, 实行土地用 途管制。

土地利用变化包括一种利用方式向另一 种利用方式的转变及利用范围、强度的改变。 由上节可知, 锡林郭勒地区在 2000 年后耕地 持续减少, 草地增加。根据时空变化特征分析 可知, 锡林郭勒草原生长季 NDVI 总量呈波动 式增长趋势, 增加速率为 0.002 。正好符合了
近年锡林郭勒草原植被覆盖状况总体好转的 结论。

2000 年后耕地数量减少, 减少部分的大部 分都转入了草地。林地增加的面积大部分来自 于草地, 减少的部分也主要转入草地。居民点 和工矿用地增加的面积主要来自于耕地和草 地, 减少的部分转入于草地和林地。大体上来 讲, 耕地的转出量为最大, 草地的转入量为最 大。

\section{5. 结论}

进入 90 年代以来, 全球变化研究领域逐渐加 强了对土地利用/土地覆盖变化的研究。因为 人类通过与土地有关的自然资源的利用活动, 改变地球陆地表面的覆盖状况, 而覆盖状况对 区域水循环、生态和生物多样性都会有影响, 且不仅仅会局限于地区。

利用 2000 至 2014 年间 15 年的 MODIS NDVI 数据估算了锡林古勒草原的植被覆盖 率, 分析了锡林郭勒草原植被覆盖率的时间变 化、空间格局和空间变化及其与土地利用变化 的关系, 得出了以下结论:

(1) 锡林郭勒草原植被覆盖率整体变化 趋势是由东向西逐渐减小, 东部地区略高于西 部地区, 南部地区略高于北部地区。15 年间锡 林郭勒草原植被覆盖率总体呈现出波动式上 升趋势, 增加速率为 0.002 。与近年锡林郭勒 草原植被状况总体好转的结论一致[17-21]。

（2）2000 年至 2014 年, 15 年间植被覆 盖度不同的等级向其更高一层转移, 同时搞覆 盖度地区中出现了极低或者低覆盖度小地图。 这为锡林郭勒盟各旗县地区开展相应的生态 保护和土地利用工作方面提供了重要的依据 及方向。

（3）土地利用/土地覆盖变化所带来的环 境问题已被大众所发觉、承认。政府也正在通 过改变土地利用结构, 在改善生态环境。锡林 郭勒盟所实施的土地方面的政策也已经起到 了显著地效果, 所以锡林郭勒草原植被覆盖率 近年才会呈现出上升趋势

(4) 可以利用遥感技术测出某一地区的 植被覆盖动态监测数据, 监测其变化情况, 对 其大范围的草地生长状况做出一个比较完整 的评估分析。为后期的草地生态保护和其地区 的土地利用规划提供建议及依据。

\section{Acknowledgements}

This study was supported by National Natural Science Foundation of China (No. 2013ZD08) 
Risk Analysis and Crisis Response in Big Data Era (RAC-16)

Inner Mongolia Normal University major project to cultivate special project (No.2013ZDPY04).

\section{致谢}

本研究得到了内蒙古自然科学基金 (2013ZD08)、内蒙古师范大学科研基金重大培 育项目(2013ZDPY04)的资助。通讯作者: 道日 敖(1994-), 女, 内蒙古通辽人, 硕士研究生, 研究方向为土地资源管理专业。

Emai1:982147095@qq.com

\section{参考文献}

[1] 陈秋红.中国北方草地资源可持续管理: 基 于制度和政策视角的研究.中国社会科学 院农村发展研究所,2013

[2] Parmesan C, Yohe G, A globally coherent fingerprint of climate change impacts across natural systems. Nature, 2003,421(6918): $37-42$.

[3] Gitelson A A, Kaufman Y J, Stark R, et al. Novel algorithms for remote estimation of vegetation fraction. Remote Sensing of Environment, 2002, 80(1):76-87.

[4] 甘春英, 王兮之, 李保生,等. 连江流域近 18 年来植被覆盖度变化分析. 地理科学, 2011(8):1019-1024.

[5] 岳瑞红. 基于 MODIS 数据的蒙古高原土 地覆盖分类研究. 内蒙古师范大学, 2010 .

[6] 甄霖, 刘纪远, 刘雪林, 等. 蒙古高原农牧 业系统格局变化与影响因素分析. 干早区 资源与环境,2008,22(1):144 - 151.

[7] 王菱, 甄霖, 刘雪林, 等. 蒙古高原中部气 候变化及影响因素比较研究. 地理研究, 2008, 27(1):171-180.

[8] 魏云洁, 甄霖, Ochirbat Batkhishig, 等. 蒙 古高原生态服务消费空间差异的实证研究 资源科学, 2009, 31(10):1677-1684.

[9] 赵金霞, 赵玉洁, 徐灵芝,等. 蒙古气旋产 生强沙尘暴的诊断分析. 中国沙漠, 2011, 31(5):1309-1315.

[10] 包刚, 覃志豪, 包玉海, 等. 1982-2006 年 蒙古高原植被覆盖时空变化分析. 中国沙 漠, 2013, 33(3):918-927.

[11] Cheng X, Sun H, Yuan Z, et al. Flood Disaster Risk Assessment and Spatial Distribution Characteristics along the Yangtze River in Anhui Province. Journal of Risk Analysis and Crisis Response, 2014, 4(4):238-242.

[12] Li X, Wu W, Lv D, et al. Research on
Risk Assessment and Regionalization of Forest and Grassland Fire. Journal of Risk Analysis \& Crisis Response, 2012, 2(1):69-77.

[13]Holben B N. Characteristics of maximum-value composite images from temporal AVHRR data.International Journal of Remote Sensing,1986,7 (11) ;1417-1434

[14] 包塔娜. 锡林郭勒盟土地利用动态变化 研究. 内蒙古师范大学, 2011 .

[15] 卓莉，曹金金，陈晋,等. 锡林郭勒草原生态 恢复工程效果的评价. 地理学报, 2007, 62(5):471-480.

[16] 吴睿子，甄霖，杜秉贞,等. 内蒙古生态保 护工程对农牧民生产生活方式的影响. 资 源科学, 2012, 34(6):1049-1061.

[17] 艳燕, 阿拉腾图雅, 胡云锋,等. 19752009 年锡林郭勒盟东部地区草地退化态势及其 空间格局分析. 地球信息科学学报, 2011, 13(4):549-555

[18] 布仁, 包玉海. 基于 MOD13A1 的锡林郭 勒草原近 13 年植被覆盖变化分析, 风险分 析和危机反应中的信息技术--中国灾害防 御协会风险分析专业委员会年会. 2014.

[19]秦福荣, 那音太. 基于 MODIS 数据的内蒙 古 2000-2011 年植被变化时空特征分析(英 文), 风险分析和危机反应中的信息技术-中国灾害防御协会风险分析专业委员会年 会. 2014 .

[20] 玉山，都瓦拉，包玉海,等. 基于相对湿润 指数的近 1980-2010 年锡林郭勒盟 5-9 月 干旱趋势分析, 风险分析和危机反应中的 信息技术--中国灾害防御协会风险分析专 业委员会年会. 2014. 